\title{
Hipersensibilidad dentinal: Una revisión de su etiología, patogénesis y tratamiento
}

\section{Dentine hypersensitivity: A review of its aetiology, pathogenesis and management}

\author{
Ardila Medina CM*
}

\section{RESUMEN}

La hipersensibilidad dentinal se define como un dolor que surge desde la dentina expuesta y representa diferentes entidades clínicas. La presentación de casos en personas jóvenes se está incrementando particularmente al parecer debido a dietas acidogénicas, malos hábitos, técnicas de cepillado deficientes y el uso indiscriminado de productos de blanqueamiento dental. La exposición dentinal se puede deber a procesos, tanto físicos como químicos, que conducen a la pérdida ya sea del esmalte y el cemento o del tejido gingival. Los factores causales rara vez actúan aisladamente e incluyen erosión, atrición, abrasión, bruxismo, blanqueamiento, medicación, envejecimiento, condiciones genéticas, recesión gingival y enfermedad periodontal. Existe un amplio rango de productos disponibles para el tratamiento con el fin de ocluir los túbulos dentinales o bloquear la transmisión neural desde la pulpa. La mayoría de opciones son reversibles y usan agentes químicos tales como fluoruros, oxalato, sales de estroncio o potasio o agentes adhesivo dentinarios. Las opciones no reversibles deben ser empleadas solamente después de intentar varias veces las reversibles. Esto usualmente incluye la colocación de restauraciones permanentes, ajustes oclusales o cirugía periodontal. El diagnóstico adecuado, las estrategias de manejo y la educación del paciente son cruciales para el manejo de cualquier intervención.

Palabras clave: Hipersensibilidad dentinaria, tratamientos desensibilizantes.

\section{SUMMARY}

Dentine hypersensitivity is defined as pain arising from exposed dentine and represents a distinct clinical entity. Reported cases are increasing particularly among the younger age groups and are thought to be due to acidogenic diets, destructive habits, poor tooth brushing techniques, and the increased use of tooth whitening products. Dentine exposure may be due to a number of processes, both physical and chemical, that lead to either loss of enamel/ cementum or loss of gingival tissue. These causative factors seldom act in isolation and include erosion, abrasion, attrition, abfraction, bruxing, bleaching, medication, ageing, genetic conditions, gingival recession, and periodontal disease. There are diverse range of treatment products available, which aim at either occluding the dentinal tubules or blocking the neural transmission from the pulp. Most reversible options make use of chemical agents such as fluorides, oxalate, strontium or potassium salts, or dentinebonding agents. Non-reversible options should only be employed after one or more of the reversible options have been attempted. These usually involve placement of permanent restorations, occlusal adjustments or periodontal flap surgery. Careful diagnosis, patient counseling and management strategies are crucial to the success of any intervention.

Key words: Dentine hypersensitivity, desensitizing treatment.

Fecha de recepción: 1 de septiembre 2008.

Aceptado para publicación: 11 de septiembre 2008.

* Profesor Asistente. Universidad de Antioquía.

Presidente de la Sociedad Colombiana de Periodoncia-Regional Antioquía.

Ardila Medina CM. Hipersensibilidad dentinal: Una revisión de su etiología, patogénesis y tratamiento. Av. Odontoestomatol 2009; 25 (3): 137-146. 


\section{INTRODUCCIÓN}

Cuando el diente se encuentra situado en su posición anatómica ideal, el margen gingival está dispuesto levemente en sentido coronal a la unión amelocementaria y sólo la superficie del esmalte está en contacto con el medio oral. Cuando el cemento y la dentina quedan expuestos como consecuencia de la recesión gingival, los estímulos externos táctiles, térmicos o químicos pueden desencadenar una sensación dolorosa conocida como hipersensibilidad dentinaria (HD) (1). Además de la recesión gingival existen otras causas que pueden ocasionar sensibilidad y se exponen mas adelante, a su vez la recesión gingival es producida por factores como cepillado vigoroso, malposición dentaria, tratamientos de ortodoncia, entre otros, lo cual ocasiona HD.

Es un síndrome doloroso a menudo de carácter crónico con exacerbaciones agudas caracterizado por respuesta dolorosa a estímulos que en condiciones normales no causarían molestias. Addy y colaboradores (2), definen la hiperestesia dentinal como un dolor transitorio derivado de la exposición de la dentina que aparece con relación a un estímulo químico, osmótico, térmico o táctil y que no puede ser asociado a ningún otro tipo de patología dental. Estudios epidemiológicos reportan que la HD afecta a una de cada siete personas (3).

La sensibilidad está causada por los túbulos dentinarios abiertos que comunican a la pulpa con la cavidad oral y su grado de sensibilidad está influenciado por el número y tamaño de los túbulos abiertos $(4,5)$. Su origen es multifactorial y el tratamiento para dicho proceso es poco satisfactorio a pesar de haberse usado múltiples métodos para este fin. La fuerte respuesta dentinal se manifiesta como dolor, el cual es de tipo agudo, palpitante y quemante originado en un estímulo nocivo que activa nervios específicos, transmitiendo la sensación hacia el sistema nervioso central, donde es interpretado como dolor. La HD es más frecuente en zonas vestibulares y los dientes mas afectados son los caninos y bicúspides (6-8). Los casos graves de sensibilidad pueden motivar un cambio emocional y alterar el estilo de vida de las personas afectadas.

El objetivo de este artículo es proporcionar al profesional información útil para el diagnóstico y manejo clínico de la HD en su práctica diaria.

\section{ETIOPATOGENIA}

Las causas de hipersensibilidad más frecuentes son: superficies dentinales expuestas por erosión, abrasión o recesiones gingivales, trauma oclusal, falta de unión amelocementaria dejando expuesta la dentina, alisados radiculares repetitivos, caries cervical, tratamientos quirúrgicos periodontales, hipoplasias del esmalte y estímulos externos como el frío, calor, ácidos, presión, químicos además de altas soluciones osmóticas que pueden causar movimiento del fluido en los túbulos dentinales e inducir dolor en los nervios pulpares $(9,10)$.

Existen también varias hipótesis que académicamente explican la patogenia de la sensibilidad dentinal:

1. Teoría del mecanismo transductor (11): Existen nervios y terminaciones nerviosas a lo largo de los odontoblastos de los túbulos dentinales, en predentina y dentina. Es por ello, que el dolor puede ser transmitido desde la unión amelocementaria hasta las terminaciones nerviosas cerca de la pulpa dental, a través de la membrana plasmática del proceso odontoblástico o por el movimiento del líquido que rodea el mismo.

2. Teoría de la modulación (12, 13): Bajo un estímulo irritante sobre la dentina, los odontoblastos se lesionan con la posterior liberación de una variedad de agentes neurotransmisores como las proteínas vasoactivas y aminas productoras de dolor.

3. Teoría de control de entrada y vibraciones (14): Cuando se irrita la dentina, todos los nervios pulpares se activan por vibraciones. Las fibras mielínicas voluminosas pueden resistir y acomodarse a las sensaciones, por el contrario, las fibras mas pequeñas no lo hacen y transmiten el dolor.

4. Teoría hidrodinámica $(15,16)$ : Cuando se aplica un estímulo externo a la dentina se origina un movimiento del líquido tubular dentinal, el cual va a estimular los procesos nerviosos en la zona pulpar de la dentina transmitiendo el impulso doloroso. El calor produce expansión y desplazamiento del líquido al interior del túbulo dentinal, por el contrario, el frío y el tacto actúan de forma inversa para producir el dolor. 
Los estímulos que desencadenan principalmente el dolor son estímulos térmicos como el aire, frío y calor; estímulos químicos como alimentos dulces, ácidos y cítricos; y estímulos mecánicos como el cepillado dental, hábitos orales, instrumentos dentales, retenedores de dentaduras parciales removibles y el blanqueamiento dental $(17,18)$. Estos estímulos térmicos son incitadores hidrodinámicos eficaces por las diferencias en los coeficientes de expansión o contracción de los líquidos pulpodentinarios y sus receptáculos en el esmalte y dentina, es decir, la aplicación de frío produce una contracción volumétrica más rápida del líquido en el túbulo dentinal que la ocurrida en la dentina. Esta diferencia de cambios volumétricos ocasiona presiones intrapulpares negativas y tal vez intradentales que desplazan los mecanorreceptores y producen dolor $(17,18)$. El calentamiento tiene un efecto contrario, pero causa el mismo resultado. Los estímulos por aire causan deshidratación y dolor debido al movimiento del fluido tubular y al desplazamiento resultante de los odontoblastos (19).

Los estímulos químicos son producidos por una distorsión de la membrana celular del odontoblasto, ocasionando liberación de cloruro de potasio para despolarizar la fibra nerviosa asociada (20). Un alimento dulce o ácido en contacto con dentina expuesta produce dolor aún cuando el estímulo se retire, debido a la deshidratación que genera (21). Algunos estímulos químicos tienen sus efectos sobre el tejido pulpar desmineralizando la dentina alterando su función (22).

Finalmente, los estímulos mecánicos son principalmente ocasionados por que el cepillado dental remueve tejidos dentales y ocasionan recesión gingival. Factores como el método y frecuencia de cepillado, tipo de cepillo y el dentífrico usado se relacionan con los efectos producidos sobre los tejidos duros y blandos (23-25).

\section{MECANISMOS FISIOLÓGICOS Y PATOLÓGICOS DE LA RESPUESTA PULPAR}

La pulpa tiene mecanismos naturales de defensa para protegerse de los estímulos irritantes. Uno de ellos es la producción de dentina secundaria, que toma lugar después de la formación total de la raíz (26). La dentina peritubular también aumenta presentándose la esclerosis dentinaria y puede llegar a obliterar el túbulo dentinal (27).

La dentina puede autodesensibilizarse naturalmente por la mineralización peritubular y por la adhesión de componentes de la saliva sobre los túbulos dentinales (28). La oclusión natural de la dentina peritubular por los cristales de calcio, es la forma fisiológica como el diente minimiza la sensibilidad dentinaria, de esta forma, disminuirá el movimiento del fluido intratubular y según la teoría hidrodinámica, reducirá el dolor que pueda ocasionar el estímulo externo aplicado.

\section{TRATAMIENTO}

Desde sus orígenes la humanidad ha luchado contra el dolor en todas sus manifestaciones. Existen entonces diferentes métodos para calmar la odontalgia originada en la dentina: unas empíricas y otras científicas. Pierre Fauchard, en 1728, informó que Hipócrates fue el primero en aconsejar el uso regular de dentífrico con base de carbonato de calcio. En 1866, Francis (29) propuso usar revestimientos cavitarios para fomentar la producción de dentina secundaria. Así a medida que ha transcurrido la historia diferentes métodos han aparecido para tratar la HD.

En el tratamiento de la hipersensibilidad se deben tener en cuenta aspectos como el diagnóstico diferencial y la identificación de factores etiológicos y predisponentes (30).

1. Diagnóstico diferencial: La HD varía en intensidad, desde leve hasta muy dolorosa. En algunas personas puede ser tolerable, mientras que en otras es un grave problema que puede afectar su calidad de vida, sus hábitos de higiene oral y el tipo de alimentación. Para en el enfoque terapéutico correcto es fundamental realizar diagnóstico diferencial con otras causas que pueden ocasionar dolor en los dientes, es así como, la atención a la descripción de las características del dolor es esencial para establecerlo. Primordialmente es necesario hacer diagnóstico diferencial con los trastornos pulpares que son irreversibles y requieren un tratamiento radical. El dolor de la HD es 
localizado y de corta duración y el paciente señala un punto, el de la patología pulpar es mas difuso, intenso, pulsátil y de larga duración, y el paciente señala un área.

2. Identificación de factores etiológicos y predisponentes (31): La identificación de los factores etiológicos abrasivos, erosivos y los factores concordantes predisponentes son esenciales para la prevención de la HD. El control de estos factores es fundamental para el correcto enfoque terapéutico. Para que haya hipersensibilidad tiene que haber exposición de la dentina la cual puede ser debida a pérdida del esmalte/cemento o a pérdida de tejidos periodontales. La pérdida del esmalte puede ocurrir por atrición debida a hábitos de actividad parafuncional como el bruxismo, puede aparecer por abrasión asociada a la dieta o al cepillado dental y puede surgir por erosión debida a factores relacionados con la dieta $(32,33)$, particularmente ácidos, o también por la combinación de algunos factores expuestos anteriormente.

\section{Productos desensibilizantes (34)}

Estos productos pueden actuar en primer lugar ocluyendo los túbulos dentinales con bloqueo del movimiento del fluido que participan en los mecanismos hidrodinámicos, mediante la producción de una capa de barro dentinario o mediante aplicación de productos. El otro mecanismo de acción se produce alterando la actividad neural de la pulpa disminuyendo la excitabilidad.

1. Oclusión de los túbulos dentinales con bloqueo del movimiento de fluido: estudios "in vitro" e "in vivo" han valorado fisiológica y estructuralmente el efecto de diferentes tratamientos sobre la permeabilidad dentinaria (34-37). Estas investigaciones han valorado el nitrato potásico al 5\%, el cloruro de estroncio al $10 \%$, el fluoruro sódico al $2 \%$, combinación del fluoruro sódico al $2 \%$ y cloruro cálcico al $2 \%$, el nitrato de plata, el oxalato monopotásico al 3\%, el oxalato dipotásico al $30 \%$ y una combinación de estos dos últimos. En teoría cualquier tratamiento que bloquee los túbulos dentinales tiene que reducir la hipersensibilidad (34-37). Los resultados de estos estudios han mostrado lo siguiente (34- 37):
- El efecto de las sales de oxalato es significativamente superior al de los demás productos ensayados.

- El efecto del oxalato monopotásico al 3\% es superior al del oxalato dipotásico al $30 \%$ e inferior al de la combinación de los dos productos sin que las diferencias sean estadísticamente significativas.

- El nitrato de plata, no usado actualmente por su efecto pigmentador, tiene un efecto destacado aunque inferior al de las sales de oxalato.

- El nitrato potásico al 5\%, el cloruro de estroncio al $10 \%$ y el fluoruro sódico al $2 \%$ no tienen efectos sobre la disminución de la permeabilidad capilar.

2. Alteración de la actividad neural de la pulpa con disminución de la excitabilidad. Las conclusiones de algunos estudios realizados con el fin de evaluar este proceso se describen a continuación (35- 40):

- El ion potasio reduce la actividad neural intradental independientemente del ion con el que se combine. No es sorprendente la actuación de este ion ya que la elevación extracelular de su concentración produce despolarización de la membrana celular inactivando la actividad sensorial por 15-20 segundos.

- El ion nitrato no es efectivo como reductor de la actividad neural intradental.

- El ion sodio no solamente no es efectivo como reductor de la actividad neural sino que por el contrario produce excitabilidad neural.

- El oxalato férrico fue efectivo en la reducción de la actividad neural intradental.

- Las soluciones con cationes divalentes también son efectivas en la disminución de la actividad neural. El cloruro cálcico y el cloruro magnésico fueron efectivos pero inferiores a las soluciones que contienen ion potasio. El cloruro de estroncio, ingrediente de dentífricos, fue efectivo solo a concentraciones elevadas que no se pueden usar clínicamente y su efecto fue inferior al del oxalato y nitrato potásico utilizado también en pastas dentales. La tabla 1 presenta algunas soluciones y productos evaluados en ensayos clínicos para resolver la HD. 


\section{Productos desensibilizantes aplicados por el paciente}

La utilización de productos desensibilizantes por parte del paciente es una de las formas más prácticas para el tratamiento de la hipersensibilidad dentinaria y su prescripción es el método más comúnmente empleado. Se usan para ello el nitrato potásico al $5 \%$, el cloruro de estroncio al $10 \%$ y los fluoruros.

El nitrato potásico al $5 \%$ se emplea en dentífricos y enjuagatorios y diversos estudios se han realizado para comprobar su eficacia desensibilizante (39-40). Los iones potasio al parecer se difunden a lo largo de los túbulos dentinales disminuyendo la excitabilidad de los nervios intradentales, alterando su membrana $(39,40)$. Sin embargo, la eficacia del nitrato de potasio para reducir la HD, no es soportada fuertemente por la literatura, según un metaanálisis realizado por Poulsen y colaboradores (41). El cloruro de estroncio al $10 \%$ también se ha utilizado ampliamente en dentífricos, su mecanismo de acción no es muy claro y se ha reportado que se uniría a la dentina y produciría una descalcificación acelerada de la matriz dentinaria con obturación de los túbulos dentinarios, pero los estudios sobre disminución de permeabilidad capilar no han mostrado resultados alentadores (39).

La prescripción de productos que contienen flúor se ha vuelto muy popular. La aplicación de sales de flúor produce precipitación de cristales de fluoruro cálcico $(41,42)$, cuyo tamaño es inferior al de los cristales de oxalato cálcico que obturan los túbulos dentinarios pero son eliminados rápidamente tras la aplicación. Estudios clínicos han mostrado cierto grado de efectividad en la reducción de hipersensibilidad tras la utilización a largo plazo de los fluoruros $(41,42)$, pero los informes sobre oclusión de túbulos dentinarios han mostrado resultados poco satisfactorios $(41,42)$. La mayoría de cremas dentales con productos desensibilizantes incorporan flúor principalmente por el efecto estabilizador en la capa de barrido dentinario (smear layer) y no por su efecto en la reducción de hipersensibilidad $(41,42)$.

\section{Productos desensibilizantes aplicados por el odontólogo}

La aplicación de productos desensibilizantes por el clínico complementa el tratamiento aplicado por el paciente. Este producto debe proporcionar alivio de la sintomatología, debe ser fácil de aplicar, bien tolerado por el paciente y no debe dañar las estructuras dentales $(41,42)$. Su objetivo es ocluir los túbulos dentinarios bloqueando el movimiento de fluido. Las sales de oxalato bloquean eficazmente los túbulos dentinarios y su utilidad clínica ha sido demostrada (42). Los iones oxalato reaccionan con iones calcio en el fluido dentinal formando cristales insolubles de oxalato cálcico. El oxalato potásico es un producto ampliamente utilizado por profesionales como aplicación tópica, que bloquea eficazmente los túbulos dentinales y que además ofrece la ventaja de contener iones potasio que difunden a zonas profundas de los túbulos para producir desensibilización, alterando la excitabilidad neural pulpar (34-36).

\section{TABLA 1.- SOLUCIONES Y PRODUCTOS EVALUADOS EN ENSAYOS CLÍNICOS}

\begin{tabular}{|c|c|c|}
\hline Tipo & Químico/concentración & Estudio \\
\hline Fluoruro & Sodio, estañoso e hidrógeno & (48) \\
\hline Nitrato de potasio & $\begin{array}{l}\text { Soluciones } 1-15 \% \\
\text { Gel } 5-10 \%\end{array}$ & $\begin{array}{l}(49) \\
(50)\end{array}$ \\
\hline Oxalato & $\begin{array}{l}\text { de Potasio al } 3 \% \\
\text { Férrico al } 6,8 \%\end{array}$ & $\begin{array}{c}(51,52) \\
(53)\end{array}$ \\
\hline Fosfato de calcio & $\begin{array}{l}1,5 \text { moles de cloruro de calcio por litro al } 5 \% \text { más } 1 \text { mol de oxalato } \\
\text { de potasio al } 1 \%\end{array}$ & (54) \\
\hline
\end{tabular}


La aplicación de flúor mediante ionoforesis ha sido utilizada con el objetivo de aprovechar el potencial eléctrico para transferir iones flúor a zonas mas profundas de los túbulos dentinales. Es una técnica difícil y complicada cuya efectividad clínica no ha sido demostrada en estudios clínicos controlados $(41,42)$. El uso de corticosteroides e hidróxido de calcio han sido reportados en la literatura para conseguir alivio a la sensibilidad, pero sus resultados han sido controvertidos $(41,42)$.

Diferentes barnices se han empleado para ocluir los túbulos dentinarios pero solo consiguen un efecto temporal pues pueden ser fácilmente eliminadas por el cepillado (42). Se han empleado resinas y adhesivos con el fin de sellar los túbulos dentinales para prevenir estímulos dolorosos que afecten la pulpa; esta puede ser una terapia alternativa cuando otras formas de tratamiento no han dado buenos resultados, siempre y cuando, se sigan estrictamente las indicaciones dadas por el fabricante, en cuanto al proceso de adhesión $(41,42)$. Los cementos de ionómero de vidrio también se han empleados para controlar la hipersensibilidad pero no hay estudios clínicos controlados que avalen su eficacia clínica $(41,42)$. Los clínicos deben ser conscientes de que los ensayos clínicos que emplean materiales adhesivos desensibilizantes tienden a ser pragmáticos y por lo general no son doble ciegos por la dificultad de su diseño metodológico. La tabla 2 presenta productos evaluados recientemente cuya hipótesis es la oclusión de túbulos dentinales para el tratamiento de la HD.

Continuamente aparecen nuevos productos con el fin de corregir y/o controlar la sensibilidad, como

\section{TABLA 2.- ADHESIVOS Y RESINAS EVALUADOS EN ENSAYOS CLÍNICOS}

\begin{tabular}{|l|c|}
\hline Tipo & Estudio \\
\hline Barniz fluoruro & $(55)$ \\
Resina y ácido oxálico & $(48,56)$ \\
Primeros, sellantes & $(55,57,58,59)$ \\
Ácido y primer & $(58)$ \\
Ácido, primer y adhesivo & $(59)$ \\
Primer y adhesivo & $(55)$ \\
\hline
\end{tabular}

por ejemplo el dimetacrilato de polietilenglicol combinado con glutaraldehido en solución acuosa y diferentes tipos de biovidrios, cuya efectividad por medio de estudios a largo plazo no ha sido reportada en la literatura. Por esta razón, el odontólogo debe ser precavido con la utilización de materiales que apenas se introduzcan en el mercado con el fin de controlar la HD y debe exigir informes de diferentes estudios clínicos controlados aleatorizados a las casas productoras, con el fin de comprobar con evidencia científica sus resultados.

La terapéutica con rayos láser también ha sido usada con el objetivo de ocluir los túbulos dentinarios $(43,44)$. Estudios estructurales muestran efectos variables, consiguiendo obturación de túbulos en zonas que aparecen glaseadas junto a túbulos totalmente abiertos y cráteres en dentina, existiendo el riesgo de aumentar la sensibilidad (45).

La cirugía estética periodontal que involucra colgajos desplazados coronalmente, es una alternativa muy importante a tener en cuenta cuando la superficie radicular expuesta causa al paciente hipersensibilidad dentinal. Existen varias técnicas quirúrgicas que se pueden llevar a cabo para lograr cubrir las recesiones disminuyendo la hipersensibilidad, mostrando además muy buenos resultados estéticos (46). Las figuras 1 a 4 muestran una recesión antes y después de cirugía estética mucogingival. Si la HD está relacionada con una abrasión, un ajuste oclusal puede ser efectivo (46).

\section{EDUCACIÓN DEL PACIENTE}

El paciente debe ser instruido y educado en cuanto a la dieta, técnica de cepillado y registro de placa bacteriana para controlar mejor los efectos de la hipersensibilidad.

Los ácidos de la dieta son capaces de causar lesiones erosivas en la estructura dentaria, removiendo cemento y abriendo los túbulos dentinales, entonces se deben hacer sugerencias al paciente en cuanto a cantidad y frecuencia del consumo de alimentos con contenido ácido. Una recomendación muy importante es pedirle al paciente que anote los alimentos que consume por una semana 


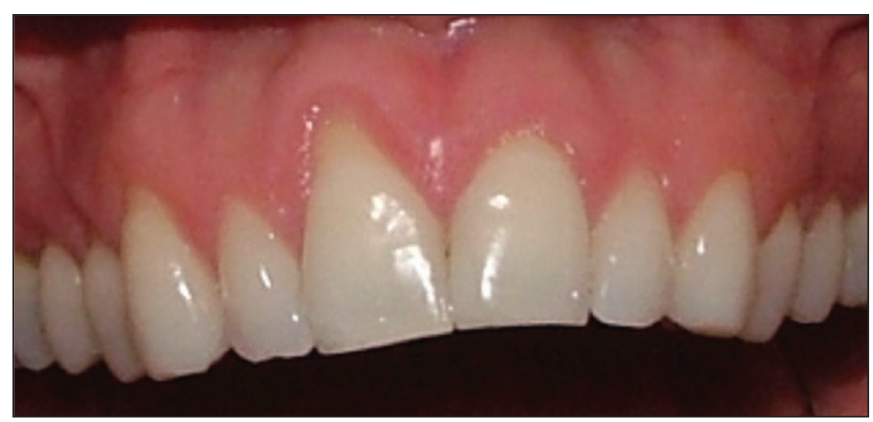

Fig. 1. Recesión gingival.

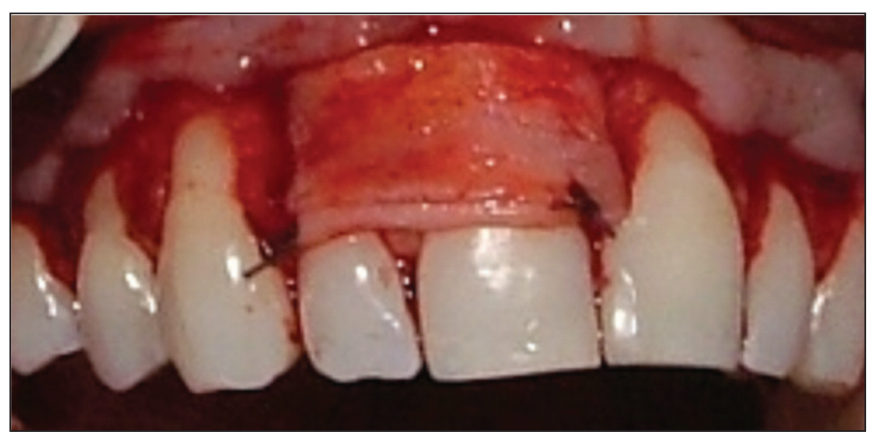

Fig. 2. Injerto de tejido conectivo.

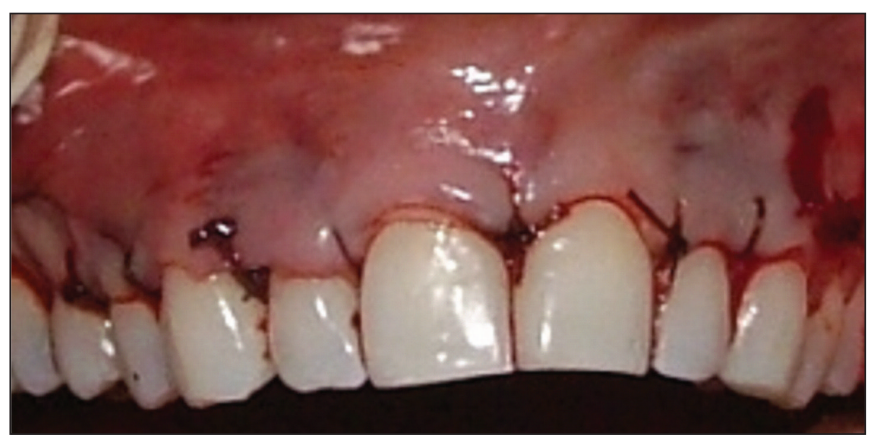

Fig. 3. Colgajo posicionado coronalmente.

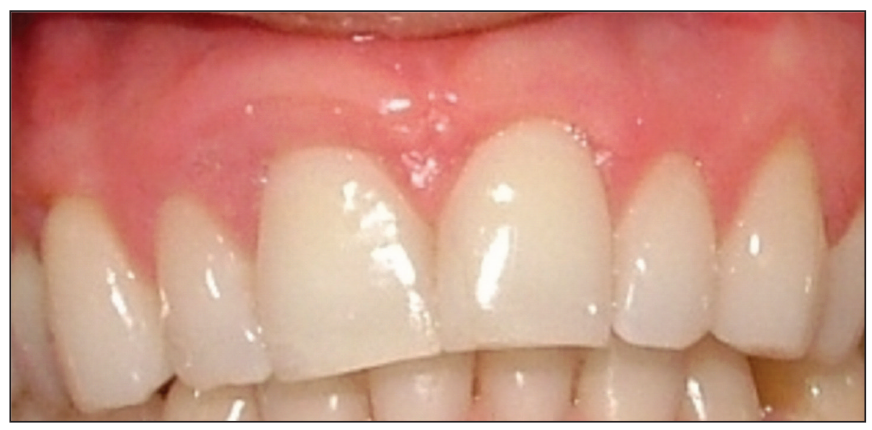

Fig. 4. Cubrimiento de la recesión. para luego ser evaluados por el profesional con el fin de determinar el grado de acidez de su dieta, ya que la remoción del smear layer puede ser debido a ciertos componentes de la misma $(41,42$, 46). Es así como algunos investigadores han encontrado que los vinos, frutas cítricas, jugo de naranja y el yogur fueron capaces de remover esta capa in Vitro (32) Una técnica de cepillado incorrecta es uno de los factores etiológicos de la sensibilidad, se debe entonces instruir al paciente sobre un procedimiento adecuado para prevenir pérdidas posteriores de dentina. La técnica de cepillado en combinación con la descalcificación de la dentina superficial es capaz de acelerar la pérdida de la estructura dentaria (47). Debido a que la pérdida de la dentina se incrementa cuando el cepillado es ejecutado inmediatamente después de la exposición del diente a los alimentos ácidos, los pacientes deben ser instruidos para no realizarlo tan pronto consuman los cítricos sino esperar un tiempo prudencia (47).

La saliva contiene iones fosfatos y calcio capaces de contribuir a la formación de depósitos minerales dentro de los túbulos dentinales expuestos. La presencia de placa bacteriana puede interferir enormemente en este proceso, debido a que es productora de ácidos, disolviendo cualquier mineral y abriendo los túbulos. Esto es corroborado por estudios en donde los pacientes que han mantenido efectivos controles de placa han reportado menos sensibilidad (46).

\section{CONCLUSIONES}

Los clínicos deben tener en cuenta los factores causales que cumplen un papel importante en el inicio y localización de la HD. Es fundamental identificar estos factores para que regímenes preventivos sean incluidos en el plan de tratamiento. El manejo activo de la HD frecuentemente maneja una combinación de cuidados en casa con terapias en la consulta odontológica. En la práctica, el tratamiento instaurado dependerá de la severidad percibida de la condición y del número de dientes involucrados. En todos los casos, se recomiendan visitas periódicas para evaluar la evolución de la HD y tomar las medidas pertinentes según sea el caso. 


\section{BIBLIOGRAFÍA}

1. Dowell P, Addy M. Dentine hypersensivity: A review, etiology, symptoms and theories of pain production. J Clin Periodontol 1983;10: 341-50.

2. Addy M, Mostafa P, Absi EG, Adams D. Cervical dentine hypersensivity: etiology and management with particular reference to dentifrices. Proccedings of Symposium on hipersensitive dentine: Origin and management: Ed Rowe $\mathrm{NH}$. University of Michigan 1985:43-64.

3. Graf H, Galasse R. Morbidity, prevalence and intraoral distribution of hipersensitive teeth. J Dent Res 1977;56:A 162.

4. Absi EG, Addy M, Adams D. Dentin hipersesivity. A study of the patency of dentinal tubules in sensitive and no sensitive cervical dentine. J Clin Periodontol 1987;14:280-4.

5. Pashley DH. Mechanisms of dentin sensitivity. Dent Clin North Am 1990;34:449-93.

6. O'leary TJ, Drake RB, Jividen GJ, Allen MF. The incidence of recession in young males: relationship to gingival and plaque scores. J Dent 1987;15: 242-8.

7. Kallestal C, Uhlin S. Buccal attacment loss in swedish adolescent. J Clin Periodontol 1992;19: 485-91.

8. Orchardson R, Collins WJN. Clinical features of hipersensitive teeth. Br Dent J 1987;162: 253-6.

9. Echeverry M. Causas y tratamiento de la hipersensibilidad radicular. Universitas odontológicas 1982;1:17-25.

10. Hampf G. Hipersensitivity due to stress. Resth Progr 1989;36:265-7.

11. Avery JK, Rapp R. Investigation of the mechanism of neural impulse transmission in human teeth. Oral Surg 1959;12:190-8.
12. Duran C. Inervación intrapulpar, sensibilidad dentinaria e hipersensibilidad dentinaria. Rev FOC 1988;17-39.

13. Turker M. A method for studyng the peripheral mediators of the dental pain induced by electrical stimulation. Arch Int Physiolo Biochem 1975;83: 553-7.

14. Van H. Phisiology of yhe human dental pulpo. Oral Surg 1971;31:1-12.

15. Brammstrom M, Andstrom A: The hydrodinamics of the dentinal tubule and of pulp fluid. Caries Res 1967;I:310-5.

16. Kawabata M, Hector MP, Davis GR, Parkinson CR, Rees GD, Anderson P. Diffusive transport within dentinal tubules: an X-ray microtomographic study. Arch Oral Biol 2008; 53: 736-43.

17. Brough K. The effectiveness of iontoporesiss in reducing dentin hipersensivity. J Am Dent Assoc 1985;111:761-5.

18. Hewlett ER. Etiology and management of whitening-induced tooth hypersensitivity. J Calif Dent Assoc. 2007;35:499-506.

19. Matthews B. The ultraestructure and receptor transductions mechanism of dentin. Progr Brain Res 1988;74:69-74.

20. Bender I. Pulp biology conference. A discussion. JOE 1978;4:32-7.

21. Echeverry J, Jimenez ID. Fundamentos de investigación. Rev CES 1991.

22. Jaramillo A. Hipersensibilidad dentinal. Act odontol 1992;15:17-30.

23. Goldman HM. Dentinal sensitivy: A periododontis perspective. Comp Cont Educ Dent 1982;3: 110-2.

24. Stein RB: Nerve and muscles membranes. NY Plenum press 1983;33-58. 
25. Kleinberg I.Dentinal hipersensitivity. Part I. Treatment of sensitive dentin: Comp Cont Educ Dent 1986;6:280-4.

26. Kleinberg I.Dentinal hipersensitivity. Part I. Treatment of sensitive dentin: Comp Cont Educ Dent 1987;4:35-40.

27. Karlson U. Natural desensitization of exposed tooth roots in dogs. J Dent Res 1975;54:982-5.

28. Krausser JT. Hipersensitive teeth. Etiology. J Prosth Dent 1986;56:153-6.

29. Francis CE. Sensitive dentine. Its causes and treatment. Cosmos VII. 1866.

30. Bascones A. Dolor orofacial 1997. Ed. Medico dentales. Madrid.

31. Knight T. Erosion, abrasion. J Dent Assoc S Afr 1969;24:310-4.

32. Zandim DL, Corrêa FO, Rossa Júnior C, Sampaio JE. In vitro evaluation of the effect of natural orange juices on dentin morphology. Braz Oral Res 2008;22:176-83.

33. Sauro S, Mannocci F, Watson TF, Piemontese M, Sherriff $M$, Mongiorgi R. The influence of soft acidic drinks in exposing dentinal tubules after non-surgical periodontal treatment: a SEM investigation on the protective effects of oxalatecontaining phytocomplex. Med Oral Patol Oral Cir Bucal. 2007 1;12:542-8.

34. Addy M. Etiology and clinical implications of dentine hipersensitivity. Dent Clin North Am 1990; 34:503-14.

35. Gandolfi MG, Silvia F, H PD, Gasparotto G, Carlo P. Calcium silicate coating derived from Portland cement as treatment for hypersensitive dentine. J Dent 2008;36:565-78.

36. Churchley D, Rees GD, Barbu E, Nevell TG, Tsibouklis J. Fluoropolymers as low-surfaceenergy tooth coatings for oral care. Int J Pharm 2008;352:44-9.
37. White DJ, Lawless MA, Fatade A, Baig A, von Koppenfels R, Duschner H, Götz H. Stannous fluoride/sodium hexametaphosphate dentifrice increases dentin resistance to tubule exposure in vitro. J Clin Dent 2007;18:55-9.

38. Pashley DH. Smear layer. Physiological considerations. Oper Dent 1984; 3:13-29.

39. Markowitz K. Kim S. Experimental studies of dentinal desensitizing agents. Dent Clin North Am 1990:34:491-501.

40. Markowiths K, Kim S. The role of selected cations in the desensitization of intradental nerves. Proc Finn Dent Soc 1992; 88:39-54.

41. Poulsen S, Errboe M, Hovgaard O, Worthington HW. Potassium nitrate toothpaste for dentine hypersensitivity (Cochrane Review). In: The Cochrane Library. Oxford, England: Update Software $2005 ; 1$.

42. Bartold PM. Dentinal hypersensitivity: a review. Aust Dent J 2006;51:212-8.

43. Churchley D, Rees GD, Barbu E, Nevell TG, Tsibouklis J. Fluoropolymers as low-surfaceenergy tooth coatings for oral care. Int $\mathrm{J}$ Pharm 2008;352(20):44-9.

44. Vlacic J, Meyers IA, Walsh LJ. Laser-activated fluoride treatment of enamel as prevention against erosion. Aust Dent J 2007; 52: 17580.

45. Pashley EL, Horner JA, Liu M, King S, Pstuey $\mathrm{DH}$. Effects of $\mathrm{CO} 2$ laser energy on dentin permeability. J Endodon 1992;18:257-62.

46. Sykes LM. Dentine hypersensitivity: a review of its aetiology, pathogenesis and management. SADJ 2007;62:66-71.

47. Hiatt WH, Johansen E. Root preparation I. Obturation of dentinal tubules in treatment of root hipersensitivity. J Periodontol 1972;43: 373-80. 
48. Morris MF, Morris MF, Davis RD, Richardson BW. Clinical efficacy of two dentin desensitizing agents. Am J Dent 1999;12:72-6.

49. Hodosh M. A superior desensitizer: potassium nitrate. J Am Dent Assoc 1974;88:831-2.

50. Frechoso SC, Menendez M, Guisasola C, Arregui I, Tejerina JM,Sicilia A. Evaluation of the efficacy of two potassium nitrate bioadhesive gels $(5 \%$ and $10 \%$ ) in the treatment of dentine hypersensitivity: a randomised clinical trial. J Clin Periodontol 2003;30:315-20.

51. Camps J, Pashley D. In vivo sensitivity of human root dentin to air blast and scratching. J Periodontol 2003;74:1589-94.

52. Pillon FL, Romani IG, Schmidt ER. Effect of a 3\% potassium oxalate topical application on dentinal hypersensitivity after subgingival scaling and root planing. J Periodontol 2004;75:1461-4.

53. Gillam DG, Newman HN, Davies EH, Bulman JS, Troullos ES, Curro FA. Clinical evaluation of ferric oxalate in relieving dentine hypersensitivity. J Oral Rehabil 2004;31:245-50.

54. Geiger S, Matalon S, Blasbalg J, Tung M, Eichmiller FC. The clinical effect of amorphous calcium phosphate (ACP) on root surface hypersensitivity. Oper Dent 2003;28:496-500.
55. Duran I, Sengun A. The long-term effectiveness of five current desensitizing products on cervical dentine sensitivity. J Oral Rehabil 2004;31:351-6.

56. Prati C, Cervellati F, Sanasi V, Montebugnoli L. Treatment of cervical dentin hypersensitivity with resin adhesives: 4-week evaluation. Am J Dent 2001;14:378-82.

57. Baysan A, Lynch E. Treatment of cervical sensitivity with a root sealant. Am J Dent 2003; 16(2):135-8.

58. Ferrari M, Cagidiaco MC, Kugel G, Davidson CL. Clinical evaluation of a one-bottle bonding system for desensitizing exposed roots. Am J Dent 1999;12:243-9.

59. Dondi dall'Orologio G, Lorenzi R, Anselmi M, Grisso V. Dentin desensitizing effects of Gluma Alternate, Health-Dent Desensitizer and Scotchbond Multi-Purpose. Am J Dent 1999;12: 103-6.

\section{CORRESPONDENCIA}

Carrera 47 No. 20 sur 46

Envigado Antioquia

57(4) 3348122

cmartin@odontologia.udea.edu.co 